\title{
Thermal conductivity of neon, argon, and xenon at high temperatures
}

\author{
George Ś. Springer and Elwood W. Wingeier \\ Fluid Dynamics Laboratory, Department of Mechanical Engineering, The University of Michigan, Ann Arbor, Michigan 48105
}

(Received 16 May 1972)

\begin{abstract}
Thermal conductivities $\lambda$ of neon, argon, and xenon were measured at $760 \mathrm{~mm} \mathrm{Hg}$ in the ranges $1000-1500^{\circ} \mathrm{K}$ (neon, xenon) and $1000-2500^{\circ} \mathrm{K}$ (argon). The data were correlated by expressions of the form $\lambda=a T^{b}$, where $a$ and $b$ are constants depending upon the gas. The results were compared with (1) existing data, (2) viscosity measurements $\eta$, by means of the coefficient $f=\lambda /\left(2.5 \eta C_{v}\right)$, and (3) values calculated from an extended law of corresponding states. The correlations obtained from the measurements were found to describe well the thermal conductivities of all three gases not only within the temperature ranges of the experiments but also over the range $900-2500^{\circ} \mathrm{K}$.
\end{abstract}

\section{INTRODUCTION}

In recent years, the column method has been employed by several investigators for measuring thermal conductivities of gases at high temperatures (e.g., see summaries in Refs. 1 and 2). This method was also used with success in our laboratory in determining thermal conductivity values of helium, ${ }^{3}$ argon, ${ }^{2}$ krypton, ${ }^{2}$ and nitrogen ${ }^{2}$ up to 2000 ${ }^{\circ} \mathrm{K}$, and butane ${ }^{4}$ and $n$-propane ${ }^{4}$ up to $1000^{\circ} \mathrm{K}$. In this paper we report extension of this work to neon and xenon up to $1500^{\circ} \mathrm{K}$, and argon up to $2500^{\circ} \mathrm{K}$. The first two of these gases were studied because, apparently, only one set of thermal conductivity data exists for each of them at temperatures above $1000^{\circ} \mathrm{K} .{ }^{5,6}$ The main objectives in extending the measurements for argon up to $2500^{\circ} \mathrm{K}$ was to assess the usefulness of the apparatus at such high temperatures.

\section{EXPERIMENTAL}

The design of the apparatus and the experimental procedures were given elsewhere, ${ }^{2,7}$ and will not be repeated here in detail. Only those aspects of the experiment will be described which are needed in discussing the results. Essentially, the gas (at $760 \mathrm{~mm} \mathrm{Hg}$ ) was contained between two concentric cylinders (the inner one being a filament) maintained at different temperatures and the heat transfer through the gas was measured. The thermal conductivity was calculated from the expression ${ }^{3}$

$$
\lambda\left(T_{f}\right)=\left[\ln \left(r_{o} / r_{f}\right) / 2 \pi\right]\left(d Q_{\lambda} / d T\right)_{T_{f}}\left(1+\lambda^{\prime}+\lambda^{\prime \prime}\right),
$$

where $r_{f}$ and $r_{o}$ are the radii of the filament and the outer cylinder, respectively, $T_{f}$ is the filament temperature, and $Q_{\lambda}$ is the heat conducted (per unit length of filament) through the gas. $\lambda^{\prime}$ is a correction due to the temperature drop across the outer cylinder. ${ }^{3}$ In the present measurements $\lambda^{\prime}$ was less than 0.002 . $\lambda^{\prime \prime}$ is a correction due to the temperature jump at the filament surface and may be approximated by ${ }^{3}$

$$
\lambda^{\prime \prime} \cong \frac{15}{8} \frac{2-\alpha}{\alpha} \frac{L}{r_{f}} \frac{I}{\ln \left(r_{o} / r_{f}\right)} .
$$

Thus $\lambda^{\prime \prime}$ depends both upon the thermal accommodation coefficient $\alpha$ and the mean free path $L$. The value of $\alpha$ is not known accurately and may vary from as low as 0.01 to near unity, depending upon the gas and the condition of the surface. ${ }^{8}$ For "engineering surfaces," such as used in the present experiments, $\alpha$ is expected to be in the range 0.5 to $0.8 .^{8,9}$ Assuming the lower value $(\alpha=0.5)$, for argon and xenon $\lambda^{\prime \prime}$ introduces a correction of at most $\sim 0.5 \%$ (Table I). Owing to the smallness of this correction and to our lack of knowledge of the precise value of $\alpha$, this correction was not applied to the argon or xenon data. This omission did not apepar to cause significant systematic errors in the results (see Sec. III).

For neon above $1500^{\circ} \mathrm{K}$ the correction due to $\lambda$ " becomes appreciable (Table I). In order to minimize possible errors in the neon results, only data taken below $1500{ }^{\circ} \mathrm{K}$ were considered, for which the effects of $\lambda^{\prime \prime}$ (and $\alpha$ ) could be neglected.

In addition to temperature jump, convection in the gas may also affect the accuracy of the results. To assess the magnitude of these latter effects, two columns of different diameters were used in our previous experiments. ${ }^{2,3}$ Since the results for helium, argon, krypton, and nitrogen indicated that convective effects were insignificant in both columns, the present experiments were performed

TABLE I. Extimated $\lambda^{\prime \prime}$ values $(\alpha=0.5)$.

\begin{tabular}{cccc}
\hline \hline Temp $\left({ }^{\circ} \mathrm{K}\right)$ & Ar & Ne & Xe \\
\hline 1000 & 0.0025 & 0.0053 & 0.0015 \\
1500 & 0.0038 & 0.0080 & 0.0023 \\
2000 & 0.0051 & 0.0107 & 0.0031 \\
2500 & 0.0064 & & \\
\hline
\end{tabular}


TABLE II. Constants of the relation $\lambda=a T^{b} \mathrm{~W} / \mathrm{m}^{\circ} \mathrm{K}$,

\begin{tabular}{lccc}
\hline \hline Gas & $a \times 10^{4}$ & $b$ & Range of Expts. $\left({ }^{\circ} \mathrm{K}\right)$ \\
\hline $\mathrm{Ne}$ & 9.683 & 0.685 & $1000-1500$ \\
$\mathrm{Ar}$ & 4.905 & 0.651 & $1000-2500$ \\
$\mathrm{Xe}$ & 1.140 & 0.710 & $1000-1500$ \\
\hline \hline
\end{tabular}

using only one column (designated as "large column" in Refs. 2 and 3 ).

\section{RESULTS AND DISCUSSIONS}

Thermal conductivities of neon and xenon in the range $1000-1500^{\circ} \mathrm{K}$ and of argon in the range $1000-$ $2500^{\circ} \mathrm{K}$ were determined at $760 \mathrm{~mm} \mathrm{Hg}$. The data were correlated by the expression

$$
\lambda=a T^{b}
$$

where $T$ is in degrees Kelvin. The values of the constants $a$ and $b$ for each of the three gases are listed in Table II. Equation (3) reproduces the data within an average absolute deviation of $\sim 0.2 \%$. It is noted here that for both neon and xenon, data were taken up to $2000^{\circ} \mathrm{K}$. However, the constants in Table $\Pi$ are based only on data between 1000$1500{ }^{\circ} \mathrm{K}$. As discussed in the previous section, in the case of neon, temperature jump effects introduced undesirable uncertainties in the data above $1500^{\circ} \mathrm{K}$. For xenon above $1500^{\circ} \mathrm{K}$, the term $d Q_{\lambda} / d T$ in Eq. (1) became inaccurate, because at these temperatures the steepness of the $Q_{\lambda}$ vs $T_{f}$ curve made the numerical differentiation difficult.

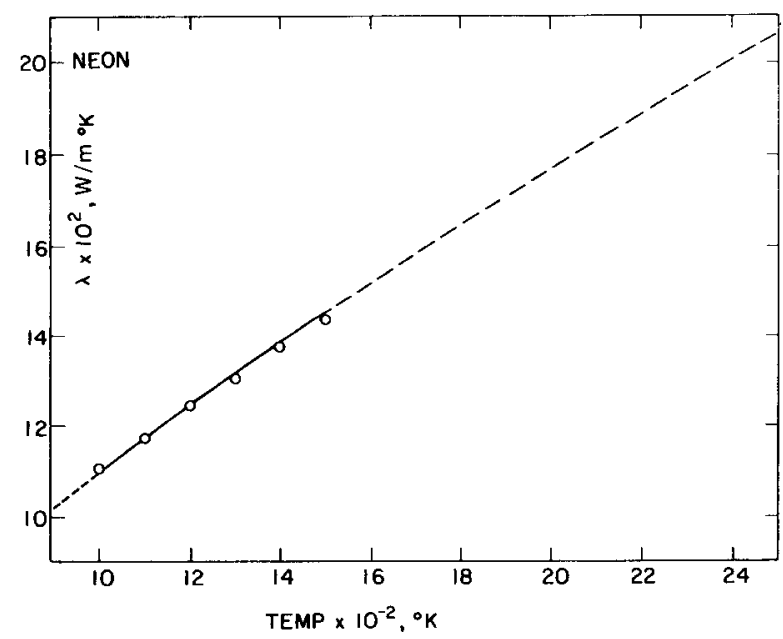

FIG. 1. Thermal conductivity of neon. - Present result (Eq. 3); - - Calculated from Eq. (3) beyond range of measurements; $O$ Saxena and Saxena. ${ }^{5}$

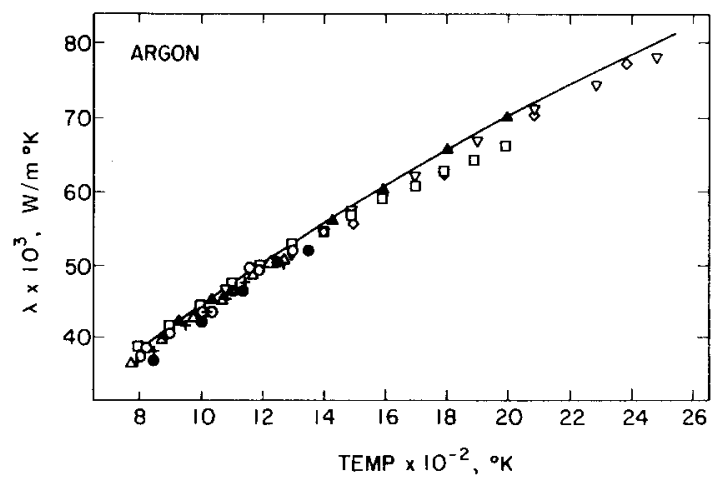

FIG. 2. Thermal conductivity of argon. - Present results (Eq. 3); A Faubert and Springer ${ }^{3} ; \nabla$ Smiley $^{10}$; $\diamond$ Collins and Mennard ${ }^{11} ;+$ Desmond $^{12} ;-$ Lee and Bonilla $^{13}$; O Saxena and Saxena ${ }^{14}$; Vargaftik and Zimina ${ }^{15}$; OVines $^{16}$; $\square$ Timrot and Umanskii. ${ }^{17}$

The thermal conductivity values given by Eq. (3) are compared to existing data in Figs. 1-3. For neon the present results agree very closely with the measurements of Saxena and Saxena. ${ }^{5}$ For argon, the present results agree well with those reported by Faubert and Springer. ${ }^{3}$ In fact, the expression given in Ref. 3 correlating the data up to $2000^{\circ} \mathrm{K}$ was found to be valid up to the limits of the present measurements $\left(2500^{\circ} \mathrm{K}\right)$. The present argon data also agree well with the thermal conductivity values obtained by all previous investigators ${ }^{10-16}$ with the exception of Timrot and Umanskii ${ }^{17}$ whose data appear to be low above $1400^{\circ} \mathrm{K}$ (Fig. 2). The xenon data of Saxena and Saxena ${ }^{6}$ differ from ours by about $5 \%-7 \%$.

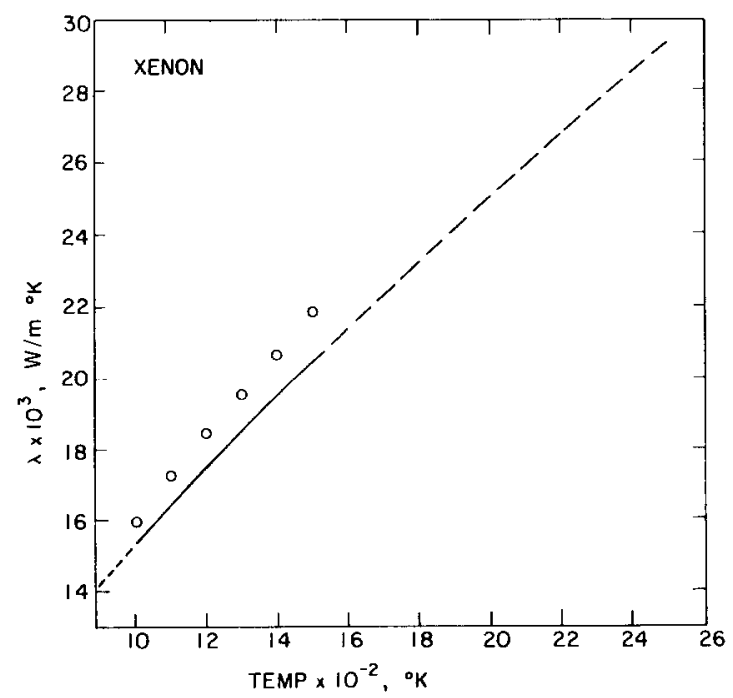

FIG. 3. Thermal conductivity of xenon. - Present result (Eq. 3); - - Calculated from Eq. (3) beyond range of measurements; O Saxena and Saxena. ${ }^{6}$ 
An error analysis of the data was made in the manner described in Ref. 7. The most probable random errors were found to range from $1 \%$ to $3 \%$. A large part of these errors were due to the numerical differentiation procedure used for evaluating $d Q_{\lambda} d T$ in Eq. (1). The systematic errors (caused mostly by uncertainties in the filament temperatures) were estimated to be less than $\sim 1 \%$. To further assess the magnitude of errors the value of the parameter

$$
f=\lambda / 2.5 \eta C_{v}
$$

was calculated. In Eq. (4) $C_{v}$ is the constant volume specific heat and $\eta$ the viscosity. Theoretically, for monatomic gases $f$ should be 1.0$1.004{ }^{18}$ Values of $f$, calculated using Eq. (3) for $\lambda$ and the viscosity data of Dawe and Smith, ${ }^{19}$ are shown in Table III. Since Dawe and Smith's measurements extend only to $1600^{\circ} \mathrm{K}$, for argon $f$ was also computed from the viscosity data of Guevara et al. ${ }^{20}$ As can be seen from Table III, the calculated values of $f$ agree closely with the theoretical ones quoted above, lending confidence to the present data. Note, that for neon there is a slight rise in $f$ with temperature, caused possibly by temperature jump effects. A similar phenomenon was also observed with helium. ${ }^{3}$ For xenon and argon there appears to be no significant systematic change in $f$. It is pointed out that for xenon the $f$ values given in Table III are within $0.5 \%$ of the theoretical value, suggesting that Saxena and Saxena's data is about $5 \%$ high (see Fig. 3).

Finally, the the rmal conductivities obtained in this investigation were compared to thermal conductivities calculated from an extended law of corresponding states proposed recently by Kestin,

TABLE III. The parameter $f=\lambda / 2.5 \eta C_{v} ; f_{1}$ is based on the viscosity data of Dawe and Smith ${ }^{19}$ and $f_{2}$ on the viscosity data of Guevara, McInteer, and Wageman. ${ }^{20}$

\begin{tabular}{|c|c|c|c|c|}
\hline \multirow{2}{*}{$\begin{array}{c}\text { Temp } \\
{ }^{\circ} \mathrm{K}\end{array}$} & \multirow{2}{*}{$\begin{array}{l}\mathrm{Ne} \\
f_{1} \\
\end{array}$} & \multirow{2}{*}{$\begin{array}{l}\mathrm{Xe} \\
f_{1}\end{array}$} & \multicolumn{2}{|c|}{ Ar } \\
\hline & & & $f_{1}$ & $f_{2}$ \\
\hline 1000 & 0.9975 & 1.002 & 1.020 & $\cdots$ \\
\hline 1100 & 1.001 & 1.000 & 1.018 & 0.9920 \\
\hline 1200 & 1.005 & 0.9988 & 1.017 & 0.9868 \\
\hline 1300 & 1.008 & 0.9983 & 1.016 & 0.9878 \\
\hline 1400 & 1.010 & 0.9982 & 1.015 & 0.9851 \\
\hline 1500 & 1.012 & 0.9987 & 1.014 & 0.9850 \\
\hline 1600 & 1.015 & 0.9993 & 1.014 & 0.9880 \\
\hline 1700 & & & & 0.9887 \\
\hline 1800 & & & & 0.9886 \\
\hline 1900 & & & & 0.9921 \\
\hline 2000 & & & & 0.9936 \\
\hline 2100 & & & & 0.9910 \\
\hline
\end{tabular}

TABLE IV. Comparison of experimental thermal conductivities [ $\lambda$ given by Eq. (3)] with values calculated from an extended law of corresponding states. ${ }^{21} \lambda$ in $10^{-1} \mathrm{~W} / \mathrm{m}{ }^{\circ} \mathrm{K}, \%=\left[\left(\lambda-\lambda_{\text {eale }}\right) / \lambda\right] 100$.

\begin{tabular}{|c|c|c|c|c|c|c|}
\hline \multirow{2}{*}{$\begin{array}{c}\text { Temp } \\
{ }^{\circ} \mathrm{K}\end{array}$} & \multicolumn{2}{|c|}{$\mathrm{Ne}$} & \multicolumn{2}{|c|}{$\mathrm{Ar}$} & \multicolumn{2}{|c|}{$\mathrm{Xe}$} \\
\hline & $\lambda$ & $\%$ & $\lambda$ & $\%$ & $\bar{\lambda}$ & $\%$ \\
\hline 900 & 1.022 & -0.44 & 0.4104 & 1.00 & 0.1427 & 0.49 \\
\hline 1100 & 1.173 & 0.11 & 0.4673 & 0.28 & 0.1645 & -0.27 \\
\hline 1300 & 1.315 & 0.40 & 0.5210 & 0 & 0.1853 & -0.39 \\
\hline 1500 & 1.451 & 0.61 & 0.5718 & -0.03 & 0.2051 & -0.45 \\
\hline 1700 & 1.581 & 0.68 & 0.6203 & -0.27 & 0.2241 & -0.38 \\
\hline 1900 & 1.706 & 0.64 & 0.6669 & -0.32 & 0.2425 & 0.23 \\
\hline 2100 & 1.827 & 0.60 & 0.7118 & -0.31 & 0.2604 & 0.55 \\
\hline 2300 & 1.944 & 0.48 & 0.7552 & -0.37 & 0.2778 & 1.01 \\
\hline 2500 & 2.059 & 0.33 & 0.7973 & -0.34 & 0.2947 & 1.27 \\
\hline
\end{tabular}

Ro, and Wakeham. ${ }^{21}$ For monatomic gases this law was found to provide a thermodynamically consistent and accurate correlation of the second virial coefficient, the thermal conductivity, the viscosity, the first virial coefficient in the density expansion of viscosity, and the coefficients of self and binary diffusion. As can be seen from Table IV, there is excellent agreement between the results given by Eq. (3) and by the law of corresponding states, even well beyond the temperature ranges for which Eq. (3) was established.

\section{ACKNOWLEDGMENTS}

The authors are grateful to Professor J. Kestin for sending them a prepublication copy of his manuscript, for providing calculated thermal conductivity values and for his many valuable comments. The authors also wish to thank Dr. J.C. Haas for his help in obtaining the argon data.

This work was supported by the National Science Foundation under Grant Number GK-14006.

${ }^{1}$ S. C. Saxena and F. E. Davis, J. Phys. E 4, 681 (1971).

${ }^{2}$ F. M. Faubert and G. S. Springer, J. Chem. Phys. 57, 2333 (1972).

${ }^{3}$ F. M. Faubert and G. S. Springer, J. Chem. Phys. 58, 4080 (1973).

${ }^{4}$ F. M. Faubert, H. Ehya, and G. S. Springer, J. Heat Transfer 94, 262 (1972).

${ }^{5}$ V. K. Saxena and S. C. Saxena, J. Chem. Phys. 48, 5662 (1968).

${ }^{6}$ V. K. Saxena and S. C. Saxena, J. Chem. Phys. 51, 3361 (1969).

${ }^{7}$ F. M. Faubert, Ph.D. thesis, The University of Michigan, Ann Arbor, MI, 1971.

${ }^{8}$ G. S. Springer, in Advances of Heat Transfer, edited by T. F. Irvine, Jr. and J. P. Hartnett (Academic, New York, 1971), Vol 7, p. 163 .

${ }^{9}$ A. Dybbs and G. S. Springer, Phys. Fluids 8, 1946 (1965). 
${ }^{10}$ E. F. Smiley, Ph.D. thesis, The Catholic University of America, Washington, DC, 1957.

${ }^{11}$ D. J. Collins and W. A. Mennard, J. Heat Transfer 88, 52 (1966).

${ }^{12}$ R. Desmond, Ph.D. thesis, University of Minnesota, Minneapolis, MN, 1968.

${ }^{13}$ C. S. Lee and C. F. Bonilla, Seventh Conference on Thermal Conductivity, National Bureau of Standards, Washington, DC, 1967.

${ }^{14}$ V. K. Saxena and S. C. Saxena, Chem. Phys. Lett. 2, 44 (1968).
${ }^{15}$ N. B. Vargaftik and N. K. Zimina, High Temp. 2, 645 (1964). ${ }^{16}$ R. G. Vines, J. Heat Transfer 82, 48 (1960).

${ }^{17}$ D. L. Timrot and A. J. Umanskii, High Temp. 4, 285 (1966). ${ }^{18}$ J. O. Hirschfelder, C. F. Curtis, and R. B. Byrd, Molecular Theory of Gases and Liquids (Wiley, New York, 1967).

${ }^{19}$ R. A. Dawe and E. B. Smith, J. Chem. Phys. 52, 693 (1970).

${ }^{20}$ F. A. Guevara, B. B. McInteer, and W. E. Wageman, Phys. Fluids 12, 2493 (1969).

${ }^{21}$ J. Kestin, S. T. Ro, and W. Wakeham, Physica (Utr.) 58, 165 (1972). 